\title{
Assessment of Knowledge and Opinions of Family Medicine Residents About the Diagnosis and Treatment of Enuresis in Children
}

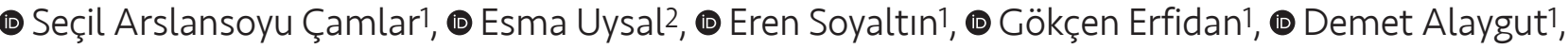 \\ (1) Fatma Mutlubaş¹, (1) Hülya Parıldar22, (1) Belde Kasap Demir3,4 \\ 'University of Health Sciences Turkey, İzmir Tepecik Training and Research Hospital, Clinic of Pediatric Nephrology, İzmir, Turkey \\ 2University of Health Sciences Turkey, İzmir Tepecik Training and Research Hospital, Clinic of Family Medicine, İzmir, Turkey \\ 3University of Health Sciences Turkey, İzmir Tepecik Training and Research Hospital, Clinic of Pediatric Nephrology, İzmir, Turkey \\ 4 İzmir Katip Çelebi University, Faculty of Medicine Department of Pediatric Nephrology and Rheumatology, İzmir, Turkey
}

\begin{abstract}
Aim: Enuresis (EN) is a common problem in childhood. Family physicians have an important role in revealing children with EN. The aim of this study was to assess the knowledge and attitude of family medicine (FM) residents regarding the diagnosis and treatment of enuresis in children.

Materials and Methods: Family medicine residents of the University of Health Sciences, İzmir Tepecik Training and Research Hospital were invited to complete a questionnaire concerning enuresis in children. Those who had completed their paediatrics rotation training were defined as group 1, and those who had not completed their paediatrics rotation as group 2 . The responses were compared between the groups.

Results: Sixty (88\%) of the FM residents agreed to complete the survey. The mean age of the participants was 28.7 (25-35) years, 38 (63\%) had completed their paediatrics rotation (group 1). The question about the age of night-time bedwetting was more often answered correctly in group $1(19 / 38)(p=0.025)$. In the question on the symptoms of non-monosymptomatic enuresis; the constipation option was marked as a symptom by only 15 of the participants $(25 \%)$, with $13(87 \%)$ being in group $1(p=0.03)$. The correct response rates to the questions about other symptoms of non-monosymptomatic enuresis, the causes of secondary enuresis, the need for treatment, treatment options and the follow-up of patients with enuresis were similar between groups 1 and 2 .
\end{abstract}

Conclusion: As a result of this study, more correct answers, which revealed adequate knowledge and experience regarding enuresis, were obtained from those who had concluded their paediatrics rotation.

Keywords: Bedwetting, child, enuresis, family medicine, paediatrics, primary care

\section{Introduction}

Enuresis (EN) is a common problem in childhood (1-3). EN Awareness is not widespread enough which may lead to a lack of help for children in need. Therefore, family medicine and primary care physicians should have sufficient knowledge regarding EN. We aimed to assess the knowledge and attitude of family medicine residents of our hospital about the diagnosis and treatment of nocturnal enuresis in children. 


\section{Materials and Methods}

This study was conducted among family medicine residents of the University of Health Sciences, İzmir Tepecik Training and Research Hospital. In June 2019, multiplechoice questions were sent to the residents via the internet. Participants in the study were asked to answer demographic questions such as their age, gender, status of their paediatrics rotation training, and eight multiple-choice questions (regarding the definition, frequency, etiology, differential diagnosis, treatment, etc) about bedwetting in children. The responses of all the participants were evaluated. Those who had completed their paediatrics rotation were defined as group 1, and those who had not completed or were currently in the process of performing their paediatrics rotation as group 2, and the responses were compared between the two groups.

Ethical approval was taken from the local Ethical Committee (2019/9-23). This study was conducted in accordance with the Helsinki Declaration.

\section{Statistical Analysis}

IBM SPSS V.22.0 software was used for statistical analysis. The data that is normally distributed are given as mean + standard deviation, and asymmetrical distributed data as median (maximum, minimum). Statistical significance was checked with parametric and non-parametric tests. A p-value less than 0.05 was considered statistically significant. The responses given by family residents who had completed (group 1) and those who had not (group 2) completed their paediatrics training were compared.

\section{Results}

Of the 68 individuals who were family medicine residents, $60(88 \%)$ agreed to fill out the questionnaire form. The mean age of the participants was 28.7 (25-35) years, $45(75 \%)$ were female. There were $38(64 \%)$ family medicine residents in group 1 .

\section{Age at Diagnosis}

The results of the answers to the question "After which age should night-time bedwetting be evaluated?" were as follows: Sixteen participants (27\%) opted for 4 years, 23 participants (38\%) opted for 5 years, 8 participants (13\%) opted for 7 years, and 13 participants (22\%) opted for the choice of "I have no idea". When the age of 5 was considered as the correct answer, the number of participants who gave this answer was $23(38 \%)$ and the number of participants who gave the wrong answers was 37 (62\%). The proportion of those who answered correctly was higher among those in group $1(19 / 38)$ than in group $2(4 / 22)$, and the difference was statistically significant $(p=0.025)$ (Table I).

\section{Prevalence}

The correct answer for question concerning "the incidence of bedwetting" was $1 / 10$. Other choices such as 1/100, 1/1,000, 1/10,000 were considered incorrect. Twentyone participants (35\%) answered this correctly. Of those who gave the correct answer, 16 had completed their paediatric rotation training and 5 had not, however the difference was not significant $(p=0.129)$.

\section{Non-monosymptomatic Enuresis}

A question for which multiple options could be selected was asked concerning the symptoms that suggest daytime urination disorders. For this question, the rates of marking each choice were evaluated separately. The rates of correctly defining the symptoms of bladder and bowel dysfunction (BBD) are shown in Table II. The correct answer rate for the symptoms was $55-81 \%$. Only 15 (25\%) participants chose constipation as a BBD symptom. 13 of these $15(87 \%)$ were in group 1 and there was a statistically significant difference with group $2(p=0.03)$.

\section{Causes of Primary Enuresis}

The choices offered and the answers given for "the etiology of primary enuresis" question are shown in Table II. Psychological causes are predominant in the etiology of secondary enuresis and $62 \%$ opted for this choice.

\section{Causes of Secondary Enuresis}

The answers given to the question of "secondary enuresis etiology" are shown in Table II. Although urinary tract infection (51\%) and psychogenic causes (42\%) were chosen more commonly, the percentage of participants who thought that neurogenic bladder might be a cause of secondary enuresis was $42 \%$. There was no statistically significant difference between the answers in groups 1 and 2 .

Table I. Answers to the questions that have only one correct choice

\begin{tabular}{|l|l|l|l|l|}
\hline & $\begin{array}{l}\text { All participants } \\
(\mathbf{n = 6 0 )}\end{array}$ & $\begin{array}{l}\text { Group 1 } \\
(\mathbf{n = 3 8 )}\end{array}$ & $\begin{array}{l}\text { Group 2 } \\
(\mathbf{n = 2 2 )}\end{array}$ & p-value \\
\hline $\begin{array}{l}\text { Urinary } \\
\text { incontinence } \\
\text { diagnosis age }\end{array}$ & 23 & 19 & 4 & 0.025 \\
\hline $\begin{array}{l}\text { Urinary } \\
\text { incontinence } \\
\text { frequency }\end{array}$ & 21 & 16 & 5 & 0.129 \\
\hline $\begin{array}{l}\text { Treatment } \\
\text { requirement }\end{array}$ & 43 & 25 & 18 & 0.542 \\
\hline
\end{tabular}


Table II. Answers to the questions that have more than one correct choice

\begin{tabular}{|l|l|l|l|l|}
\hline $\begin{array}{l}\text { Non- } \\
\text { monosymptomatic } \\
\text { enuresis }\end{array}$ & $\begin{array}{l}\text { All (\%) } \\
(\mathbf{n = 6 0 )}\end{array}$ & $\begin{array}{l}\text { Group } \\
\mathbf{1} \\
\mathbf{( n = 3 8 )}\end{array}$ & $\begin{array}{l}\text { Group } \\
\mathbf{2} \\
\mathbf{( n = 2 2 )}\end{array}$ & p-value \\
\hline Urgency & $42(70)$ & 24 & 18 & 0.108 \\
\hline Intermittent urination & $43(72)$ & 25 & 18 & 0.151 \\
\hline Daytime incontinence & $49(82)$ & 32 & 17 & 0.367 \\
\hline $\begin{array}{l}\text { Difficulty starting } \\
\text { urination }\end{array}$ & $33(55)$ & 21 & 12 & 0.584 \\
\hline Constipation & $15(25)$ & 13 & 2 & $\mathbf{0 . 0 2 8}$ \\
\hline Urine retention & $45(75)$ & 27 & 18 & 0.272 \\
\hline No idea & - & - & - & - \\
\hline $\begin{array}{l}\text { Urination for 3-7 } \\
\text { times a day }\end{array}$ & $51(85)$ & 4 & 5 & 0.183 \\
\hline
\end{tabular}

Causes of primary enuresis

\begin{tabular}{|l|l|l|l|l|}
\hline Genetic & $38(63)$ & 24 & 14 & 0.597 \\
\hline Sleeping disorders & $33(55)$ & 26 & 7 & $\mathbf{0 . 0 0 6}$ \\
\hline Psychological & $37(62)$ & 25 & 12 & 0.277 \\
\hline Nocturnal polyuria & $43(72)$ & 30 & 13 & 0.090 \\
\hline No idea & $4(7)$ & 2 & 2 & 0.468 \\
\hline
\end{tabular}

Causes of secondary enuresis

\begin{tabular}{|l|l|l|l|l|}
\hline Psychological & $49(82)$ & 30 & 19 & 0.363 \\
\hline Diabetes mellitus & $36(60)$ & 23 & 13 & 0.563 \\
\hline $\begin{array}{l}\text { Urinary tract } \\
\text { infections }\end{array}$ & $51(85)$ & 34 & 17 & 0.183 \\
\hline Diabetes insipidus & $35(58)$ & 21 & 14 & 0.360 \\
\hline Renal diseases & $29(48)$ & 20 & 9 & 0.272 \\
\hline Neurogenic bladder & $25(41)$ & 13 & 12 & 0.103 \\
\hline No idea & $3(5)$ & 1 & 2 & 0.302 \\
\hline
\end{tabular}

\section{Need for Treatment}

A single answer was required for the question "Is nocturnal enuresis a condition that should be treated in children?". Four (7\%) participants answered this question as "treatment is unnecessary because it can resolve spontaneously", 9 (15\%) as "if the child has low selfesteem, it should be treated", 2 (3\%) as "the decision of treatment is up to the family", 42 (72\%) as "it should be definitely treated"; and 2 (3\%) as "I have no idea". Of the 43 residents who thought that nocturnal enuresis in children should definitely be treated, 25 (58\%) were in group 1 but the difference between two groups was not statistically significant $(p=0.542)$.

\begin{tabular}{|l|l|l|l|}
\hline \multicolumn{2}{|l|}{ Table III. Answers to treatment options } \\
\hline Treatment options & $\begin{array}{l}\text { All (\%) } \\
\text { (n=60) }\end{array}$ & $\begin{array}{l}\text { Group 1 } \\
\text { (n=38) }\end{array}$ & $\begin{array}{l}\text { Group 2 } \\
\text { (n=22) }\end{array}$ \\
\hline BMT & 6 & 4 & 2 \\
\hline BMT + alarm & 9 & 6 & 3 \\
\hline BMT + desmopressin & 2 & 2 & 0 \\
\hline BMT + alarm + desmopressin & 8 & 7 & 1 \\
\hline BMT + oxybutynin & 1 & 0 & 1 \\
\hline BMT + alarm + oxybutynin & 4 & 2 & 2 \\
\hline Alarm + oxybutynin & 1 & 1 & 0 \\
\hline $\begin{array}{l}\text { BMT + alarm + desmopressin + } \\
\text { oxybutynin }\end{array}$ & 21 & 14 & 7 \\
\hline No idea & 8 & 2 & 6 \\
\hline BMT: Behavioural and motivational therapies & & \\
\hline
\end{tabular}

\section{Treatment Options}

It was stated that more than one answer could be given to the question "which is/are the treatment option(s) for nocturnal enuresis in children?". The choices were "behaviour therapies", "oxybutynin", "an alarm device", "desmopressin", and "I have no idea". Behavioural and motivational therapy, an alarm and/or desmopressin are the recommended treatment options of primary monosymptomatic enuresis. Fifty-one participants (85\%) opted for behavioural therapy as one of the choices and 28 (47\%) opted for oxybutynin. Only $8(13 \%)$ participants marked all three choices of behaviour, alarm and desmopressin therapy, whereas 8 (13\%) had no idea. The answers given for the treatment options are shown in Table III.

\section{Follow-up of a Patient With Enuresis}

The choices for the question "which specialities should follow and treat a child with enuresis?" were family medicine, paediatrics, paediatric nephrology, paediatric urology, and paediatric nephrology/urology specialist for unresponsive or complicated cases.

Thirty-six participants (24 from group 1 and 12 from group 2), stated that enuresis could be managed by family medicine specialists, while 50 (group 1: 31, group 2: 19) thought it should be managed by a paediatrician. Only 43 participants (group 1: 28, group 2: 17) stated that cases unresponsive to treatment should be treated by paediatric nephrologists and urologists. There was no statistical difference between groups 1 and 2 regarding the choice of speciality in the follow-up ( $p=0.354)$.

When all questions were evaluated, the rate of correct answers in those questions relating to the age at diagnosis 
of enuresis, sleep disorders in the etiology of primary enuresis and constipation symptoms as a bladder/bowel dysfunction was significantly higher in group 1. As for the other questions, there were no significant differences between the two groups.

\section{Discussion}

Enuresis, also called bedwetting, is defined as urinary incontinence during sleep in children over the age of five years (3). According to ICD-10 and DSM-V diagnostic criteria, urinary incontinence lasting for at least 3 months and occurring at least once a month is needed for diagnosis (2). When asked about the age at diagnosis, almost half of the participants gave the correct answer with the majority of the correct answers being in group 1. Having the correct information about which age to evaluate enuresis is important for health workers so that patients can be treated and monitored without delay.

Among five-year-old children, the prevalence of $\mathrm{EN}$ is $10-25 \%$. This rate regresses to $10-15 \%$ by the age of 7 , to $5 \%$ by the age of 10 and to $1 \%$ in adulthood $(1,3)$. Only one third of participants stated that they thought that enuresis is as common as to be seen in one in every 10 children. Actually, this reflects that the high number of children who suffer from enuresis is not adequately known even by physicians.

Primary enuresis occurs due to three major pathogenic mechanisms; nocturnal polyuria, detrusor hyperactivity and sleep pattern disturbance with difficulty in waking up $(2,4,5)$. In addition, genetic causes, reduced functional bladder capacity, and delayed maturation are also considered to be factors included in its etiology. Nocturnal polyuria was the most frequently selected etiology of primary enuresis. Those who evaluated sleep disorder as an etiologic factor were markedly more in the group that had completed their paediatrics rotation. This was thought to be due to the fact that children with enuresis have difficulty in waking up at night. More than half of the participants thought that psychological causes are related with primary enuresis. Two to three decades ago, enuresis was believed to be caused by psychological problems. However, currently it is thought that psychological symptoms are more the result of enuresis rather than its cause $(4,6)$.

It is known that there is a genetic predisposition for primary enuresis (7). The risk increases by $44 \%$ when either the mother or father had a history of enuresis and by up to $77 \%$ when both parents had a history of enuresis (7). Two out of three participants knew that genetics is involved in the etiology.
Secondary enuresis, which is the resumption of bedwetting after at least 6 months of bladder control, may develop in a child following a stressful period (separation of parents, history of birth of a sibling and so on) $(1,8)$. Furthermore, organic causes such as urinary tract infections, diabetes mellitus, diabetes insipidus, renal diseases and sometimes obstructive sleep apnoea, hypothyroidism, or medications (valproate) can also be involved (9). Neurogenic bladder, on the other hand, usually develops due to congenital spinal dysraphism and is among the causes of continuous incontinence. Although urinary tract infection and psychological issues are well-known causes of secondary enuresis, organic causes were found to be less known among the participants.

If a child has additional symptoms to enuresis, he/she should be investigated for signs of bladder dysfunction (2). This is because the determination of BBD is important in the treatment of these patients. The rates of correctly defining BBD symptoms ranged from $55 \%$ to $85 \%$, and the least selected choice was 'straining to urinate'. It is important to know all the symptoms of bladder dysfunction in order to fully and correctly evaluate patients. As the rectum has the same embryonic origin, bowel dysfunction can accompany bladder disorders or can aggravate symptoms of bladder dysfunction $(8,10)$. Even constipation is a part of bladder dysfunction and even a factor unfavourably affecting monosymptomatic enuresis should be investigated and treated $(6,11)$. In cases where constipation is not treated, the response rate expected from urination disorder treatment will be low. The rate of considering constipation as a symptom was rather low (25\%).

Many children with a bed-wetting problem have low self-esteem compared with their peers. Studies have shown that their school performance and quality of life scores are also low $(8,12)$. However, this is overlooked in many families, and therefore, they do not present to healthcare centres. In cases like these, every child has the right to be treated regardless of family decision or the psychological trauma on the child. The goal is to increase awareness and treatment approaches via "world bedwetting day" (www. worldbedwettingday.com). The majority (72\%) of family medicine residents thought that EN should be treated.

Behavioural and motivational therapy is the first-line treatment in primary monosymptomatic enuresis (10). These children should be a part of their treatment as motivation is important for treatment success (13). The family should be comforted by explaining that enuresis is not a condition that needs to be hidden and may resolve with treatment 
or spontaneously with time (4). Recommendations like stopping fluid intake 3-4 hours before sleeping in the evening and voiding the bladder before going to bed are included in behavioural therapy (14). Knowledge regarding behavioural approaches is especially important in order to inform these patients in their primary care.

Alarm treatment and desmopressin are recommended in evidence A at level 1 for PEN $(9,15,16)$. Alarm treatment is a non-invasive treatment method that can be selected especially in children with sleep disorders, low bladder capacity or nocturnal bladder detrusor hyperactivity (15). It is known to be as effective as desmopressin (80\%) by the end of the first month. Desmopressin, which decreases urine production through increasing water reabsorption from the renal tubules, has high efficacy starting from the first dose (16). Likewise, oxybutynin, an anticholinergic drug, can be recommended for children with non-monosymptomatic EN with bladder dysfunction. It acts by inhibiting detrusor muscle contractions; therefore, it should be given to BBD patients who need frequent voiding or who have low bladder capacity (3). It is important to use drugs with different mechanisms for appropriate indications in the eligible patients. Therefore, doctors who follow EN are expected to be fully competent in the indications, followup and adverse effects of any treatments to be applied. The treatment procedure to be followed should be planned together with the child and family.

Children who applied to a primary health care centre with incontinence and who had no symptoms of bladder dysfunction as a result of the initial evaluation can be treated by paediatricians as primary monosymptomatic enuresis (1). Maintenance treatment of these cases can be carried out by family physicians (6). Patients unresponsive to treatment or with BBD need to be referred to paediatric nephrologists or urologists for further examination and treatment. Although a high rate of participants thought that complicated cases should be referred to these specialities, they also concluded that this information should be further emphasized. For cases with PEN, those who develop psychological symptoms, such as low self-esteem because of enuresis, should be referred to receive psychological help. Similarly, for cases with secondary enuresis, those without an organic cause or thought to be accompanied with a psychiatric disorder should be evaluated by a paediatric psychiatrist. In this study, only $60 \%$ of family physicians thought that they could follow patients with EN. This suggests that family physicians should be supported with postgraduate medical training programs.

\section{Conclusion}

Primary care physicians have many opportunities to recognise and/or follow-up children with enuresis such as at routine visits or periodic health screening. Since enuresis is a serious problem that needs to be recognized and managed as early as possible, we can say that children with enuresis can have a better quality of life and their families experience less psychosocial problems when their primary care physicians have more awareness of this issue.

Ethics

Ethics Committee Approval: Ethical approval was taken from the local ethical comittee (2019/9-23) conducted in accordance with the Declaration of Helsinki.

Informed Consent: Written informed consent was obtained from the participants who volunteered to participate in the study.

Peer-review: Internally peer-reviewed.

\section{Authorship Contributions}

Concept: S.A.Ç., Design: H.P., B.K.D., Data Collection or Processing: E.U., D.A., Analysis or Interpretation: G.E., F.M., Literature Search: E.S., S.A.Ç., Writing: S.A.Ç.

Conflict of Interest: No conflict of interest was declared by the authors.

Financial Disclosure: The authors declared that this study received no financial support.

\section{References}

1. Walker RA. Nocturnal enuresis. Prim Care 2019; 46:243-8.

2. Austin PF, Bauer SB, Bower W, et al. The standardization of terminology of lower urinary tract function in children and adolescents: Update report from the standardization committee of the International Children's Continence Society. J Urol 2014; 191:1863-5.

3. Franco I, vonGontard A, De Gennaro $M$, International Children's Continence Society. Evaluation and treatment of nonmonosymptomatic nocturnal enuresis: a standardization document from the international children's continence society. J Pediatr Urol 2013; 9:234-43.

4. Haid B, Tekgül S. Primary and secondary enuresis: pathophysiology, diagnosis, and treatment. Eur Urol Focus 2017; 3:198-206.

5. Pedersen MJ, Rittig S, Jennum PJ, Kamperis K. The role of sleep in the pathophysiology of nocturnal enuresis. Sleep Med Rev 2019; 49:101228. doi: 10.1016/j.smrv.2019.101228.

6. Kuwertz-Bröking $E$, vonGontard A. Clinical management of nocturnal enuresis. Pediatr Nephrol 2018 ;33:1145-54.

7. Von Gontard A, Schaumburg H, Hollmann E, Eiberg H, Rittig S. The genetics of enuresis: a review. J Urol 2001; 166:2438-43. 
8. Von Gontard A, Baeyens D,Van HoeckeE, WarzakWJ, Bachmann C. Psychological and psychiatric issues in urinary and fecal incontinence. J Urol 2011; 185:1432-6.

9. Vande Walle J, Rittig S, Bauer S, et al, American Academy of Pediatrics, European Society for Paediatric Urology, European Society for Paediatric Nephrology, International Children's Continence Society. Practical consensus guidelines for the management of enuresis. Eur J Pediatr 2012; 171:971-83.

10. Neveus T, Eggert P, Evans ), et al. Evaluation of and treatment for monosymptomatic enuresis: a standardization document from the International Children's Incontinence Society. I Urol 2010; 183:441-7.

11. Ma $Y$, Shen $Y$, Liu $X$. Constipation in nocturnal enuresis may interfere desmopressin management success. I Pediatr Urol 2019;15:177.e1-6. doi: 10.1016/j.jpurol.2018.11.019.

12. Meydan EA, Civilibal M, Elevli M, Duru NS, Civilibal N. The quality of life of mothers of children with monosymptomatic enuresis nocturna. Int Urol Nephrol 2012; 44:655-9.
13. Bogaert $\mathrm{G}$, Stein $\mathrm{R}$, Undre $\mathrm{S}$, et al. Practical recommendations of the EAU-ESPU guidelines committee for monosymptomatic enuresis-Bedwetting. Neurourol Urodyn 2020; 39:489-97.

14. Caldwell PH, Nankivell G, Sureshkumar P. Simple behavioural interventions for nocturnal enuresis in children. Cochrane Database Syst Rev 2013:CD003637. doi: 10.1002/14651858. CD003637.pub3.

15. Glazener CMA, Evans JHC, Peto RE. Alarm interventions for nocturnal enuresis in children. Cochrane Database Syst Rev 2005:CD002911. doi: 10.1002/14651858.CD002911.pub2.

16. Glazener CM, Evans $\mathrm{JH}$. Desmopressin for nocturnal enuresis in children. Cochrane Database Syst Rev 2002:CD002112. doi: 10.1002/14651858.CD002112. 